\title{
Using Google Trends to Assess Interest in Disasters
}

\author{
Faina Linkov; Ali Ardalan; Meredith Hennon; Eugene Shubnikov; Ismail Serageldin; \\ Ronald LaPorte
}

\section{Correspondence: \\ E-mail: faina.linkov@gmail.com}

Web publication: 20 October 2010

\section{Introduction}

During a large-scale disaster caused by either natural or human-made hazards, people crave quality information about the event. Despite the cause, location, or severity of the disaster, citizens pause to learn about the disasters. Today, much of the information is gathered through Internet pathways, both for general public and healthcare providers. ${ }^{1}$

Google Trends is an Internet service that provides a unique opportunity to assess the level of disaster "interest". If material can be provided when people are most interested in learning, this can have a profound effect on increasing the public's knowledge about current and future events. Ignorance can be replaced with knowledge, and fear with understanding.

\section{Methods}

Google Trends was used to assess the Internet users' interest level in disasters. Google Trends is an analytic tool developed to assess the numbers of searches over time. For example, one could search on President Obama to determine the level of interest there has been in the President over the past three years. Google Analytics also was used to look at the level of interest in Supercourse users in JIT lectures

\section{Results}

The first search in Google Trends was on the term "disasters". There was considerable variability in searches throughout different time periods (Figure 1).

By far, the most searched disaster was that of the 2004 Indian Ocean tsunami, which was viewed by millions worldwide. Searches for disasters during the tsunami was six times the baseline. Clearly, the tsunami had an exceptional impact, however, each disaster provided a major spike in interest, much above baseline. The mention and time pattern in newspapers was roughly similar, however, there was less newspaper coverage of the tsunami than of hurricanes.

It is important to examine the tsunami effect more closely. Thus a search was performed only for "tsunami", and data are presented for 2004-2005 (Figure 2). As can be seen, the pattern of tsunami interest demonstrated that the interest peaked in only 2-3 days, and then demonstrated a precipitous decay in interest. Thus, the majority of those who performed Internet searches, did it very rapidly. As seen with the geographic variation, interest was related to where the Tsunami struck (Figure 2). However, examination of the temporal patterns of search volume indicated that all had the same pattern with a spike in interest 3-4 days after the event.

Next, the interest in "tsunami", "hurricane", "H1N1", and "earthquake" during the past six years was examined (Figure 3). Clearly, all four events had a major effect on global interest, with interest for the tsunami twice that for the earthquake in Haiti, and five times greater than Hurricane Rita. The tsunami, Hurricane Rita, H1N1, and earthquake in Haiti were very different events, and generated very different levels of interest. However, the interest curves were virtually identical. Interest shot up for 3-4 days, and then crashed. 


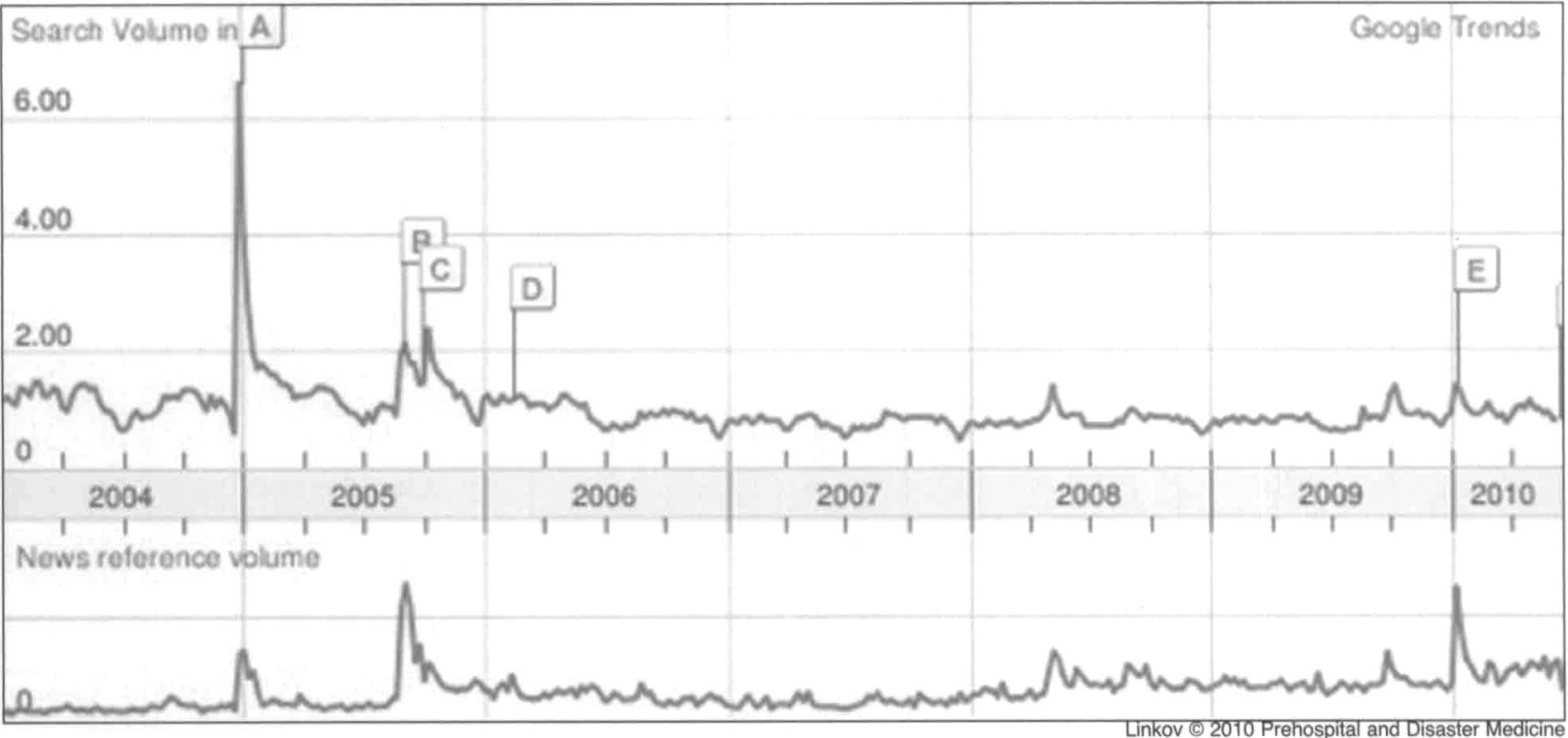

Figure 1-Searches of the term "disaster" 2004-2010

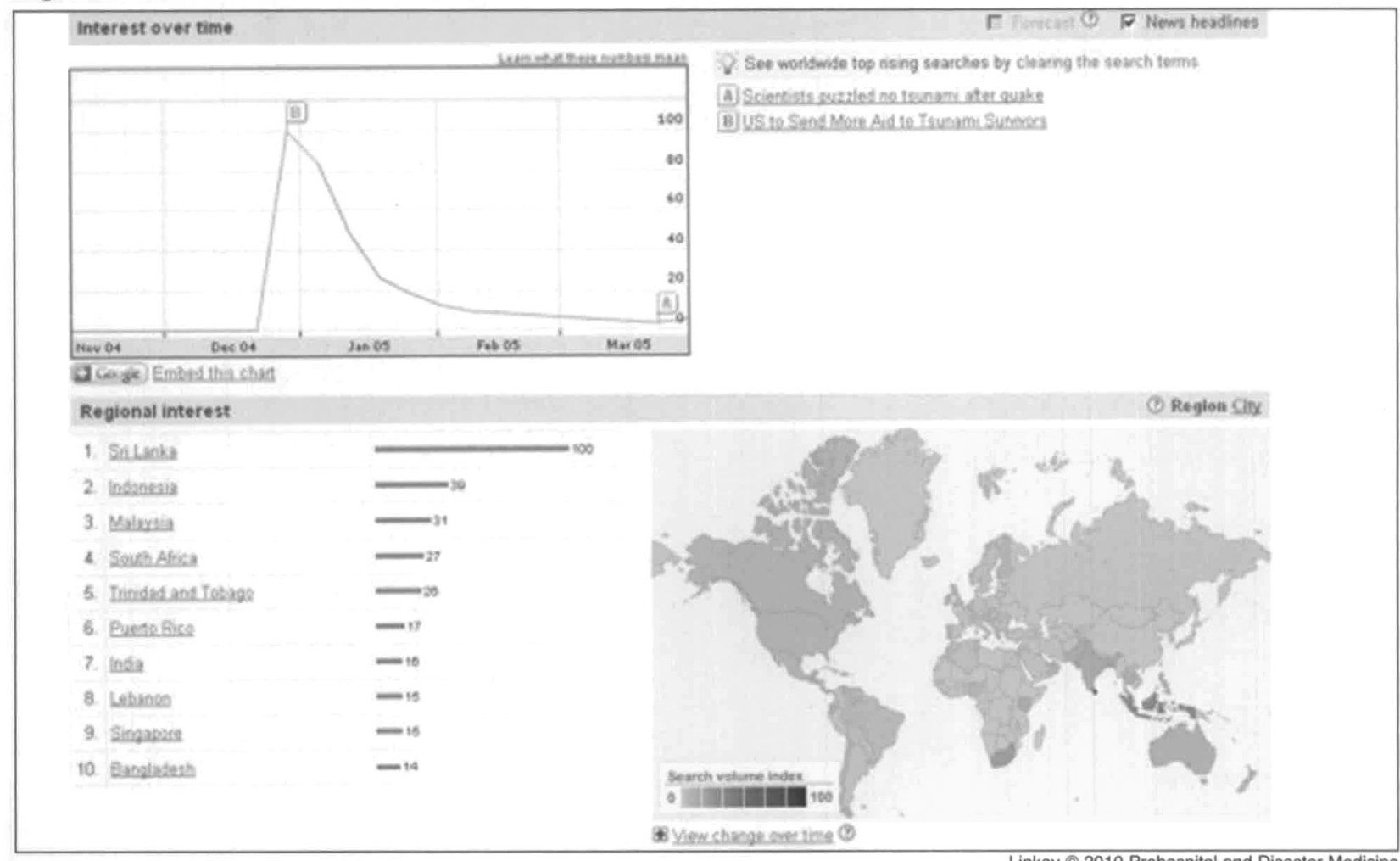

Figure 2-Searches on the term "tsunami" (2004-2005)

Linkov (c) 2010 Prehospital and Disaster Medicine

\section{Discussion}

This study is one of the first efforts to examine public interest in disasters using Google Trends. The use of Google Trends provided important information as to how to measure the interest in a specific topic, in this case, disasters. Despite the fact that disasters are very different and generate quite a large difference in interest worldwide, it appears that the fundamental curves of interest are virtually the same: 2-3 days following the event, the interest peaks, followed by a very rapid decay.

This interest level curve is very important for global disaster mitigation. If the time period following an event is to be used to educate people, we must be quick, as the interest in learning is heightened during 2-3 day period. 


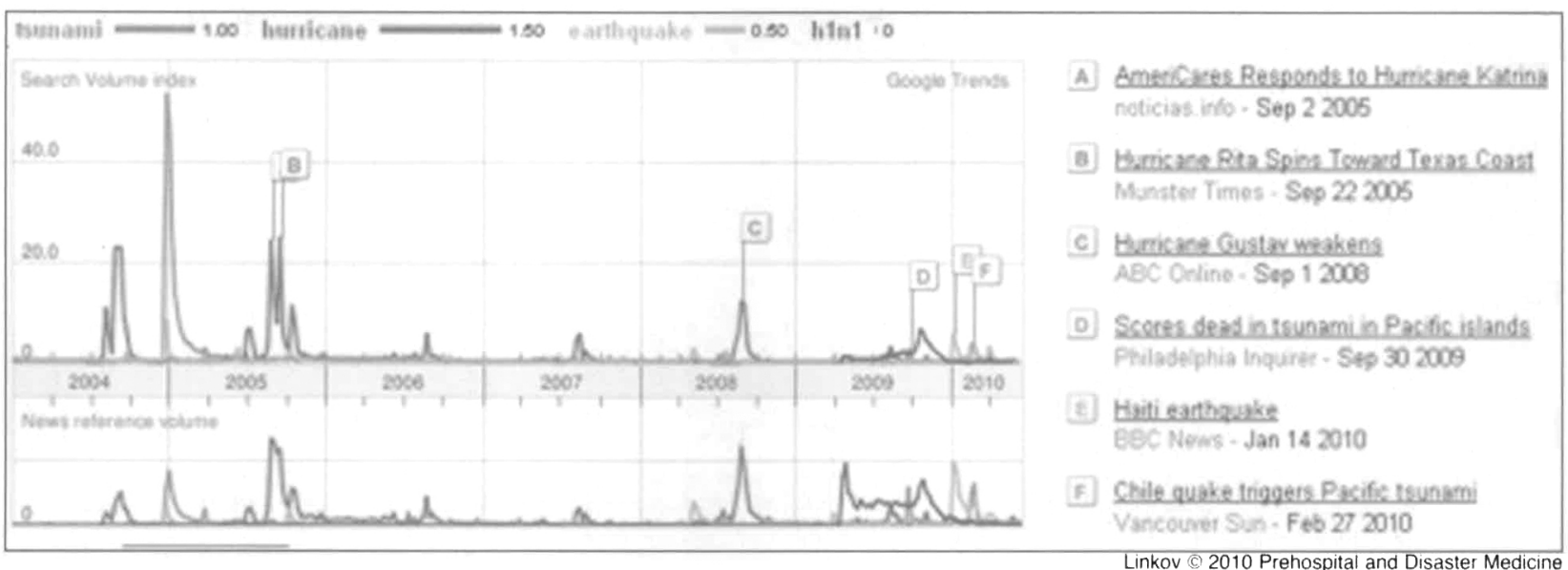

Figure 3-Interest level in tsunami, hurricane, H1N1, and Earthquake (2004-2010)

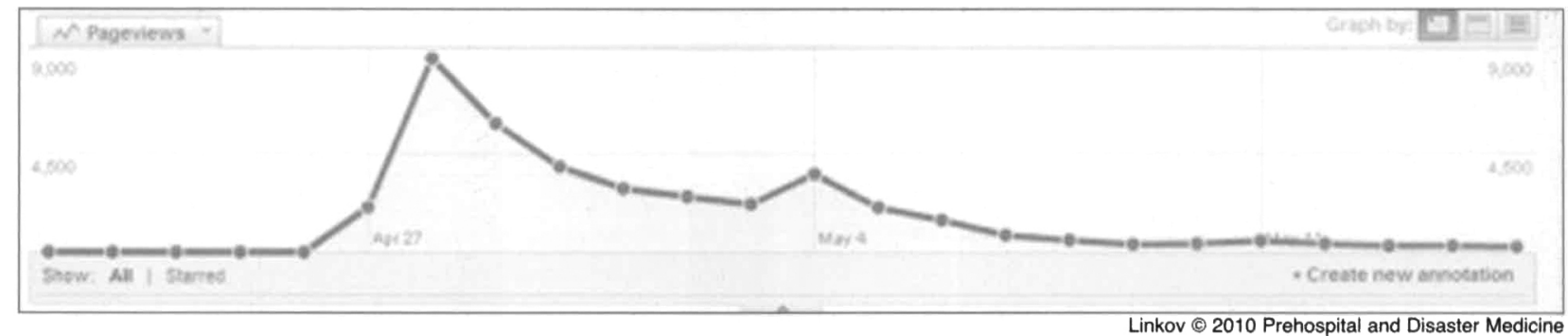

Figure 4-Patterns of access for H1N1 lecture in the Supercourse http://www.pitt.edu/ super1/lecture/lec34601/index.htm

\section{References}

1. Younger P: Internet-based information-sceking behaviour amongst doctors and nurses: A short review of the literature. Health Info Libr J 27(1):2-10.

2. LaPorte RE, Chiu WT: Strategic plan: Building a international strategy for risk reduction supercourse. Atta Neurochir Suppl 2008;101:79-81.

3. LaPorte RE, Linkov F, Villasenor T, Sauer F, Gamboa C, Lovalekar $M$, Shubnikov E, Sekikawa A, Sa ER: Papyrus to PowerPoint (P 2 P): Metamorphosis of scientific communication. BMJ 2002;325(7378):1478-1481.
4. Laporte RE, Omenn GS, Serageldin I, Cerf VG, Linkov F: A scientific supercourse. Science 2006;312(5773):526.

5. Laporte RE, Sekikawa A, Sa E, Linkov F, Lovalekar M: Whisking research into the classioom. BMJ 2002;324(7329):99.

6. Ardalan A, Linkov F, Shubnikov E, LaPorte RE: Public awareness and disaster risk reduction: Just-in-time networks and learning. Prebosp Disaster Med 2008;23(3):286-288. 